\title{
Dokuzuncu gebelikte siyam ikizi: Genel anestezi altında sezaryenle doğum
}

\section{Siamese twins at 9th pregnancy: Cesarean delivery under general anesthesia}

\author{
Berrin GÜNAYDIN*1', Gamze KILIÇARSLAN, Salih TORUK¹, Merih BAYRAM², Gökçen EMMEZ¹, \\ Nil TOKGÖZ³ ${ }^{3}$ Ömer KURTIPEK' ${ }^{1}$
}

'Gazi Üniversitesi Tıp Fakültesi, Anesteziyoloji ve Reanimasyon Anabilim Dalı, Ankara/TÜRKIYE

${ }^{2}$ Gazi Üniversitesi Tıp Fakültesi, Kadın Hastalıkları ve Doğum Anabilim Dalı, Ankara/TÜRKiYE

${ }^{3}$ Gazi Üniversitesi Tıp Fakültesi, Radyoloji Anabilim Dalı, Ankara/TÜRKiYE

\begin{abstract}
öz
Sekiz yaşayan çocuğu olan ve siyam ikizine gebe annenin genel anestezi altında sezaryenle doğumu sunularak, yüksek neonatal fatal prognoz riski nedeniyle gebe takibinin önemine dikkat çekilmesi amaçlanmıştır.
\end{abstract}

Anahtar kelimeler: ikiz gebelik; siyam ikizi; yapışık ikiz; sezaryen

\section{ABSTRACT}

It was aimed to draw attention to the importance of antenatal follow up because of the high risk of neonatal lethal prognosis by presenting cesarean delivery under general anesthesia in a parturient already having 8 children alive and siamese twin pregnancy.

Keywords: twin pregnancy; conjoined twins; siamese twins; cesarean delivery

\section{Giriş}

Siyam ikizi, döllenmiş yumurtanın organ gelişimi başladıktan sonra bölünmesine bağlı tam bir ayrılma olamaması sonucunda gelişir ve Amerika Birleşik Devletleri'nde tüm gebelikler içinde rastlanma sıklığı 1/50.000-200.000 olarak bildirilmiştir [1]. Hastanemize dış merkezden sevkle başvuran ve oldukça nadir gözlenen monoamniyotik - monokoriyonik (tek amnion keseli - tek kordonlu) siyam ikizine sahip sekiz çocuklu multipar gebenin genel anestezi altında sezaryenle doğumu sunularak, yüksek neonatal fatal prognoz riski nedeniyle gebe takibinin önemine dikkat çekilmesi amaçlanmıştır.

\section{Olgu}

Otuz-yedi yaşında (G:9, P:7) 8 yaşayan çocuğu olan gebeye dış merkezde 26. gebelik haftasında siyam (yapışık) ikizleri olduğu bildirilerek sevk edilmiştir. Hastanemizde yapılan konsey kararı sonucu mükerrer sezaryen nedeniyle 34. haftada elektif sezaryen planlanmıştır. Gebenin onamı alındıktan sonra aspirasyon profilaksisi ve standart monitörizasyonu takiben genel anestezi hazırlığı yapıldı. Operasyon masası sola çevrildi, idrar sondası takıldı. Üç dakika (dk) \%100 oksijenle preoksijenasyonu takiben intravenöz (IV) 40 mg ketamin, 150 mg propofol ve 40 mg roküronyum ile krikoid bası eşliğinde hızı seri indüksiyon ile iç çapı

\footnotetext{
Sorumlu Yazara:Berrin Günaydın, Gazi Üniversitesi Tıp Fakültesi, Anesteziyoloji ve Reanimasyon Anabilim Dalı, Ankara/TÜRKIYE E-posta: gunaydin@gazi.edu.tr Recevied: 27.07.2018 accepted: 14.10.2108

Doi: $10.18663 / \mathrm{tjcl} .448605$
} 
7 numara endotrakeal tüp kullanılarak endotrakeal entübasyon gerçekleştirildi. Kaf şişirilip, kapnograf ve bilateral oskültasyonla tüpün yeri doğrulandıktan sonra cerrahi başlatıldı. Anestezi idamesi \%1 sevofluran ve O2-hava karışımı ile sağlandı. Yaklaşık $2 \mathrm{dk}$ sonra göbek kordonu klemplendi ve yapışık ikiz bebekler doğurtularak hazır bekleyen yenidoğan pediatri ekibine teslim edildi. Göğüs kafesi ve abdomenden yapışık olan bebekler erkekti ve hemen entübe edildiler (Resim 1). Önceden yapılmış olan fetal ultrasonda ortak tek bir karaciğer olduğu ve kalplerin ise ayrı olmasına rağmen atriumların damarsal yapı ile bağlı olduğu tomografiyle de doğrulandı (Resim 2). Göbek kordonu klemplendikten sonra peroperatif analjezi idamesi için 0.05-0.2 $\mu \mathrm{g} / \mathrm{kg} / \mathrm{dk}$ remifentanil infüzyonu ve uterus tonusunun sağlanması için 500 mL RL içerisinde 10 IU oksitosin infüzyonu yapıldı.

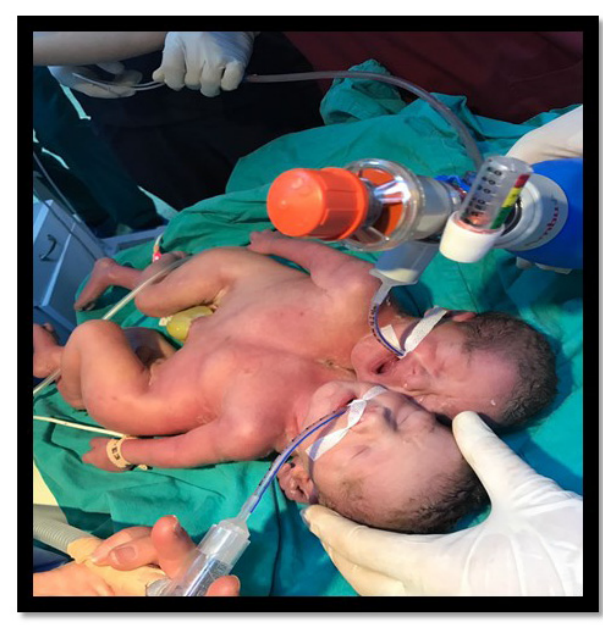

Resim 1. Yenidoğan yapışık ikizler

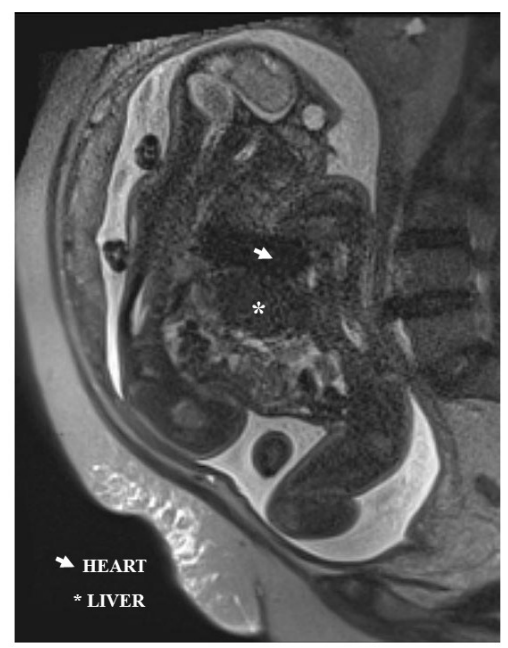

Resim 2. Yapışık ikizlerin kalp ve karaciğerini belirten görüntü

Postoperatif bulantı -kusma profilaksisi için $3 \mathrm{mg}$ granisetron IV yapıldı. Postoperatif multimodal analjezi amacıyla $20 \mathrm{mg}$ nonsteroid antiinflamatuar ve $1 \mathrm{~g}$ parasetamol iV uygulandı. Ayrıca hasta uyandırılmadan önce ultrason eşliğinde $\% 0.25$ lik $40 \mathrm{~mL}$ bupivakain ile bilateral transversus abdominis plan bloğu yapıldı. Rezidüel kas gevşetici etkisinin antagonizması için iV 2 mg/kg sugammadeks uygulanarak hasta sorunsuz ekstübe edildi ve ayılma ünitemizde takip edildi. Annenin taburculuğu postoperatif 13. günde yapıldı. Ancak yenidoğan yoğun bakımında takip edilen siyam ikizi bebekler postoperatif 45. günde eksitus kabul edildi.

\section{Tartışma}

Tek merkez olarak Sao Paulo Üniversitesi'nin 1998-2010 yılları arasında tutulan 12 yıllık kayıtlarında 36 yapışık ikizin obstetrik yönetimine ait deneyimler retrospektif olarak sunulmuştur. Fatal prognoz nedeniyle 30 olgunun cerrahi olarak ayrılmasının mümkün olmadığı belirlenmiştir. Olgulardan 14'ünde vajinal doğum ve 16 'sında sezaryenle doğum yapılmıştır. Legal gebelik terminasyonu talep eden 19 olgudan 14'ünde terminasyon gerçekleştirilmiştir [2]. Siyam ikizlerinde yapışıklığın olduğu bölgeye göre embriyolojik sınıflama yapılmıştır. Yapışıklığın en belirgin yeri kraniyum (kraiopagus), kafa (sefalopagus), göğüs (torakopagus), umbilikal (omfalopagus), lateral (parapagus), popo (pigopagus) kalça (iskiyopagus), omurga (rakipagus) olmasına göre adlandırılmaktadır [3]. Literatürde siyam ikizlerinde yaklaşık olarak \%70 oranında torakopagus gözlendiği bildirilmiştir. Kardiyak defektin derecesine göre tip A (kalpler ayrı), tip B (perikardiyal füzyon), tip C (atriyal füzyon) veya tip D (ventriküller füzyon) olarak sınıflandırmaktadır [2]. Bizim olgumuz torakopagus tip A gibi kabul edilse de atriyumların damarsal yapıyla füzyonu nedeniyle tip $C$ özelliği de göstermektedir. Dış merkezde 26.gebelik haftasında teşhis konduktan sonra sevkle bize başvurduğunda terminasyon istemi olmadığı için sezaryenle doğurtulan siyam ikizlerine düzetme ameliyatı şansı verilmek istense de yenidoğan yoğun bakımında postoperatif 45. günde kaybedilmiştir.

Yaşayan sağlıklı 8 çocuğu olan bir anne, ülkemizde oldukça çok nadir gözlenen ve hastanemizde bir ilk olan siyam ikizleri genel anestezi altında sezaryenle doğurtulmuştur. Takipsizlik nedeniyle çok geç tanı aldığı için terminasyon yapılamamıştır. Sağlıkla taburcu edilen annenin prognozu iyi olmasına rağmen bebeklerde prognoz fatal seyretmiştir. Sonuç olarak çok kötü neonatal sonuçları olan bu tip nadir gözlenen gebeliklerin olanaksızlıklar nedeniyle erken tespit edilemediği ve antenatal terminasyonunun yapılamadığı durumlarda fetal kardiyak defektin durumuna göre postnatal planlanan yapışıklığı ayırma cerrahisi amacıyla doğum gerçekleştirilebilir. Ancak asıl amaç gerekli takipler ve önlemlerle mümkünse bu noktaya gelmekten kaçınılması yönünde olmalıdır.

\section{Çıkar çatışması / finansal destek beyanı}

Bu yazıdaki hiçbir yazarın herhangi bir çıkar çatışması yoktur. Yazının herhangi bir finansal desteği yoktur

\section{Kaynaklar}

1. Edmonds LD, Layde PM. Conjoined twins in United States, 19701977. Teratology 1982; 25: 301

2. Brizot ML, Liao AW, Lopes LM, Okumura M, Marques MS, Krebs V, Schultz R, Zugaib M. Conjoined twinspregnancies:experience with 36 cases from a single center. Perinatal Diagnosis 2011;31:1120-25.

3. Spencer R. Anatomic description of conjoined twins: a plea for standardized terminology. J Pediatr Sy-urg 1996; 31: 941-44. 